\title{
BMJ Open 'Who Cares?' The experiences of caregivers of adults living with heart failure, chronic obstructive pulmonary disease and coronary artery disease: a mixed methods systematic review
}

Miriam Catherine Noonan, ${ }^{1}$ Jennifer Wingham, ${ }^{2}$ Rod S Taylor ${ }^{3}$

To cite: Noonan MC,

Wingham J, Taylor RS. 'Who Cares?' The experiences of caregivers of adults living with heart failure, chronic obstructive pulmonary disease and coronary artery disease: a mixed methods systematic review. BMJ Open 2018;8:e020927. doi:10.1136/ bmjopen-2017-020927

- Prepublication history and additional material for this paper are available online. To view these files, please visit the journal online (http://dx.doi. org/10.1136/bmjopen-2017020927).

Received 1 December 2017 Revised 30 May 2018 Accepted 7 June 2018

A Check for updates

(c) Author(s) (or their employer(s)) 2018. Re-use permitted under CC BY. Published by BMJ.

${ }^{1}$ European Centre for Environment and Human Health, University of Exeter Medical School, Knowledge Spa, Royal Cornwall Hospital, Truro, UK

${ }^{2}$ Royal Cornwall Hospitals NHS Trust, Research, Development and Innovation, F37, Knowledge Spa, Royal Cornwall Hospital, Truro, Cornwall \& University of Exeter, Exeter, UK

${ }^{3}$ University of Exeter Medical School, Exeter, UK

Correspondence to Miriam Catherine Noonan; mn354@exeter.ac.uk

\section{ABSTRACT}

Objective To assess the experiences of unpaid caregivers providing care to people with heart failure (HF) or chronic obstructive pulmonary disease (COPD) or coronary artery disease (CAD). Design Mixed methods systematic review including qualitative and quantitative studies. Data sources Databases searched: Medline Ebsco, Psyclnfo, CINAHL Plus with Full Text, Embase, Web of Science, Ethos: The British Library and ProQuest. Grey literature identified using: Global Dissertations and Theses and Applied Sciences Index and hand searches and citation checking of included references. Search time frame: 1 January 1990 to 30 August 2017.

Eligibility criteria for selecting studies Inclusion was limited to English language studies in unpaid adult caregivers (>18 years), providing care for patients with HF, COPD or CAD. Studies that considered caregivers for any other diagnoses and studies undertaken in low-income and middle-income countries were excluded. Quality assessment of included studies was conducted by two authors.

Data analysis/synthesis A results-based convergent synthesis was conducted.

Results Searches returned 8026 titles and abstracts. 54 studies-21 qualitative, 32 quantitative and 1 mixed method were included. This totalled 26453 caregivers who were primarily female $(63 \%)$, with median age of 62 years. Narrative synthesis yielded six concepts related to caregiver experience: (1) mental health, (2) caregiver role, (3) lifestyle change, (4) support for caregivers, (5) knowledge and (6) relationships. There was a discordance between paradigms regarding emerging concepts. Four concepts emerged from qualitative papers which were not present in quantitative papers: (1) expert by experience, (2) vigilance, (3) shared care and (4) time.

Conclusion Caregiving is life altering and complex with significant health implications. Health professionals should support caregivers who in turn can facilitate the recipient to manage their long-term condition. Further longitudinal research exploring the evolution of caregiver experiences over time of patients with chronic cardiopulmonary conditions is required.

Trial registration number CRD42016053412
Strengths and limitations of this study

- This mixed methods systematic review provides the opportunity for a broadened and deeper understanding of the qualitative and quantitative literature on the experiences of unpaid caregivers' providing care to people with heart failure, chronic obstructive pulmonary disease and coronary artery disease.

- This review provides an integration of the type and extent of caregiver's experiences and predictors of caregiver's experiences.

- To maximise applicability we included studies from higher income countries only.

> Quality of evidence limited by assessment of caregiver experience at single point of time and there is need for future studies that employ longitudinal or repeated measures design.

\section{INTRODUCTION}

A caregiver is anyone providing unpaid care, to a friend or family member who is unable to care for themselves. ${ }^{1}$ This may be emotional support; someone to talk to, or practical support; dressing wounds, mobility assistance or medication checking. ${ }^{2}$ There are 43.5 million caregivers in the USA, 2.86 million in Australia and 6.5 million in the UK. ${ }^{3}$ Between 2001 and 2011, the number of unpaid caregivers in the UK grew at a faster rate than population growth. ${ }^{4}$ The annual value of unpaid care provided to an individual with a chronic illness is estimated to be $£ 132$ billion. $^{5}$

Focus groups examining a caregivers' life conducted by 'The Institute of Public Care' (2017), based at Oxford Brookes University; described caregivers as the 'Skilled Helper' performing a series of roles. ${ }^{6}$ Seltzer and $\mathrm{Li}$ describe a dynamic process of transitions to being a caregiver. ${ }^{7}$ These transitions comprise participating in the role before identifying as 
a caregiver, acceptance of the role, engaging in it with awareness and sometimes moving beyond the caregiving role when the patient moving to paid care settings or bereavement occurs. This process is not linear and people move through the different transitions at varying rates. Acknowledging this, it is imperative for caregivers to receive a caregiver needs assessment as legally stipulated by the 2014 Care Act. ${ }^{8}$ Additionally, the National Institute for Health and Care Excellence clinical guidelines for heart failure (HF) (CG108) ${ }^{9}$ and chronic obstructive pulmonary disease (COPD) (CG101) ${ }^{10}$ both recommend that family members or caregivers are provided with support and included in discussions about care.

Cardiopulmonary disease is a primary cause of illness. Cardiovascular disease is responsible for $45 \%$ deaths in Europe $^{11}$ and one in four deaths in the USA. ${ }^{12}$ By 2020 , COPD is projected to be in the global top five of diagnoses causing years lost through early mortality or disability-adjusted life years. ${ }^{13}$ Caregivers of patients with HF have a multitude of unmet needs due to fluctuations in the trajectory of $\mathrm{HF}^{14}$ COPD has frequent unplanned hospital admissions and a high morbidity rate. ${ }^{15}$ Caregivers experience depressed mood, greater anxiety and increased subjective burden when their support needs are not met. ${ }^{16}{ }^{17}$ The unpredictability of HF and COPD leads to caregivers constantly adjusting their role, creating a need to continuously reassess what caregiver needs are. ${ }^{18}{ }^{19}$ Spousal caregivers of patients with myocardial infarction experience increased levels of stress, lifestyle impact and emotional distress. ${ }^{20}$ Caring for coronary artery bypass graft patients in tasks such as monitoring and provision of emotional support increased caregiver burden to a level described as moderate. ${ }^{21}$ COPD and cardiovascular disease are both increasing in prevalence and frequently coexist. ${ }^{22}{ }^{23}$ We know of no systematic review that synthesises quantitative and qualitative studies to combine caregivers' experiences of people with $\mathrm{HF}$, COPD or coronary artery disease (CAD).

Using a mixed methods systematic review methodology including both qualitative and quantitative literature, this study aims to understand the experiences of adult caregivers when supporting people with HF, COPD or CAD.

\section{METHODS}

We conducted and reported this systematic review in accordance with the Preferred Reporting Items for Systematic Reviews and Meta-Analyses (PRISMA) statement. ${ }^{24}$

\section{Patient and public involvement}

There was no patient and/or public involvement in this systematic review.

\section{Study design}

This study employed a mixed methods systematic review assessing both qualitative and quantitative studies. ${ }^{25}$ The rationale for using a mixed methods review approach was multifaceted. First, to gain a qualitative assessment of the type and extent of caregiver's experiences. Second, to assess the quantitative predictors of caregiver's experiences. Third, to develop a holistic perspective of what caregiver experiences. Finally, we wanted to assess the degree of convergence between qualitative and quantitative experiences.

\section{Search strategy}

Our search strategy was designed in conjunction with a Health Services Librarian and Information Specialists. Search terms included condition-specific terms, that is, 'heart failure', 'COPD' and 'coronary artery disease', caregiver-specific, plus experience related terms, 'experience', 'quality of life' 'activities of daily living', 'occupational engagement', 'time use', 'self-efficacy', 'coping strategies', 'leisure activity', 'information exchange' and 'caregiver expectation' (see online supplementary file 1 , table 1 for complete list of search terms). Databases searched included: Medline Ebsco, PsycInfo, CINAHL Plus with Full Text, Embase, Web of Science, Ethos: The British Library and ProQuest. Grey literature was identified using Global Dissertations and Theses and Applied Sciences Index and hand searches and citation checking of included references. To ensure the contemporary nature of the evidence considered, the search time frame was January 1990 to August 2017. A single researcher (MN) initially screened titles and abstracts. Selection of full papers was performed by two researchers (MN and either JW or RST) and cross-checked with the eligibility criteria.

\section{Study selection}

Studies were included if they addressed 'caregiver experience', which was defined as encompassing the daily activities of caregivers and the impact of these activities on their lives. These were English language studies involving unpaid adult caregivers (aged $>18$ years), providing care for patients with HF, COPD or CAD living in the community and not residential settings with paid care staff. Qualitative, quantitative and grey literature studies were all included in the search strategy. Conference papers were excluded. Outcomes of interest included psychological and physical outcomes reported, occupational engagement and routine. As we sought to inform the practice of the UK and other high-income countries, we excluded studies undertaken in low-income and middle-income countries. ${ }^{26}$

\section{Data extraction}

Data extracted from retained studies included: study design, sample and recruitment, study description, method, findings, discussion and authors' conclusions and limitations. Caregiver quotes were extracted from qualitative studies. For quantitative studies, data extraction also included details of attrition and data analysis.

\section{Study quality assessment}

Qualitative studies were appraised using the Critical Appraisal Tool. ${ }^{27}$ In absence of an existing quality tool 
that could be used to appraise quantitative studies addressing the specific question of this study, a quality assessment tool was developed by the research team based on what were deemed to be the appropriate core biases, that is, (1) was the study design longitudinal (score of 1 ) or cross-sectional (score of 0); (2) how was the sample recruited? Purposive (score of 1 ) or convenience (score of $0)$; (3) was the level of attrition/response rate acceptable? Attrition of $20 \%$ /lower or response rate of $80 \%$ or above (score of 1 ) or attrition of $>20 \%$ or response rate $<80 \%$ (score of 0 ); (4) was a validated quantitative outcome(s) used? Validated (score of 1), non-validated (score of 0 ); (5) were the methods of data analysis appropriate? Multivariate (score of 1 ) or univariate (score of 0 ). Based on their quality assessment, scores were totalled and studies were ranked: 1 or 2 'low quality', 3 'medium quality' and 4 or 5 'high quality'. Data extraction and quality appraisal was first conducted by a single researcher (MN) and checked by one of two researchers (JW or RST).

\section{Data analysis and synthesis}

The methodology of mixed methods data synthesis is an emerging one and no single approach has yet been universally accepted. ${ }^{28}$ In this study, a results-based convergent design was chosen. ${ }^{29}{ }^{30}$ This requires transformation of one method into another. Due to the heterogeneity of the quantitative methods, a meta-analysis was not appropriate. Instead, applying a narrative profile formation, quantitative data were converted into qualitative data. ${ }^{31}$ Extracted data from quantitative and qualitative studies were imported into separate spreadsheets. A meta-ethnographic approach was used to synthesise qualitative studies. ${ }^{32}$ A narrative formation approach ${ }^{33}$ was used to synthesise the quantitative data into a qualitative data set. Narrative formation is a verbal description via the use of profiles of each of the studies. The five profiles are modal, average, holistic, comparative and normative. ${ }^{33}$ Table 1 provides an example of this approach. This resulted in two qualitative data sets ${ }^{34}$ from which concepts emerged. A mapping table was completed in order to provide an audit trail of how the overall concepts across all papers were derived (see online supplementary file 1 , table $2 \mathrm{a}, \mathrm{b}$ and $\mathrm{c}$ ). Initial synthesis was conducted by a single researcher (MN) and corroborated by two experienced researchers in quantitative (RST) and qualitative (JW) research.

\section{RESULTS}

\section{Study selection}

Study selection process is summarised in a PRISMA flow diagram shown in figure 1. Following removal of duplicates, the search strategy yielded a total of 8026 titles and abstracts. Of these, 242 full papers were reviewed, of which 57 papers (54 studies) were included for synthesis. A detailed summary of included studies is provided in table 2. A comprehensive outline of study results and concepts generated by each study is included in online supplementary file 2).

\section{Study characteristics}

Of the 54 studies, 21 were qualitative, 32 quantitative and 1 mixed methods. Thirty-four focused on HF, 14 COPD and $6 \mathrm{CAD}$. The total number of caregiver participants was 26453 . Caregivers were primarily female $(63 \%)$, with a median age of 62 years. Patient median age was 69 years. A summary of study characteristics is provided in table 3 .

\section{Quality assessment}

Studies of insufficient quality were excluded, qualitative papers were appraised and only high-quality qualitative studies were included. ${ }^{35}$ A total of 21 out of 193 qualitative studies were classified as high quality. Quantitative studies were classified as follows: 3 high quality, 12 medium quality and 17 low quality (see table 4(a) and (b) for quality appraisal). Given the number of high-quality qualitative studies and in accord with current guidelines for the synthesis of qualitative evidence, we limited inclusion to qualitative studies of high quality only. ${ }^{35}$ In contrast, given the low number of high-quality quantitative studies, to ensure comprehensiveness of our review, we included all quantitative studies, regardless of quality.

\section{Findings}

Six concepts relating to caregiver experience were identified: (1) mental health, (2) caregiver role, (3) lifestyle change, (4) support for caregivers, (5) knowledge and (6) relationships. Four additional concepts were identified from qualitative papers only (6) expert by experience, (7) vigilance, (8) time and (9) sharedcare (figure 2). The concepts are reflected in caregiver quotes in table 5 .

\section{Mental health}

Twenty-five quantitative, ${ }^{36-62} 20$ qualitative ${ }^{63-83}$ and 1 mixed methods ${ }^{84}$ study addressed mental health. This encompassed depression and burden. Caregivers described an internal and external conflict of emotions, recognising a psychological change within themselves and the care recipient. Maintaining hope and positivity, versus managing worries, fears and anxieties was predominant. ${ }^{62-82}$ The HF study by Pressler et al identified caregivers had moderately poor health at baseline and at 8 months but they had fewer depressive symptoms over time. ${ }^{54}$ Burden arose due to greater responsibilities. ${ }^{65} 68738182$ Yeh and Bull noted the quality of relationship and lack of family support significantly predicted greater family caregiver burden. ${ }^{53}$ Näsström et al reported caregiver burden was concerned with the future and their fears of potential demands. ${ }^{84}$ Those with greater resiliency appeared to adjust and cope better with the illness trajectory. ${ }^{64} 657677$ Caregivers described mental adjustment after an acute event. ${ }^{77}$ Living through an acute event was long lasting and some experienced post-traumatic symptoms. ${ }^{80}$ 


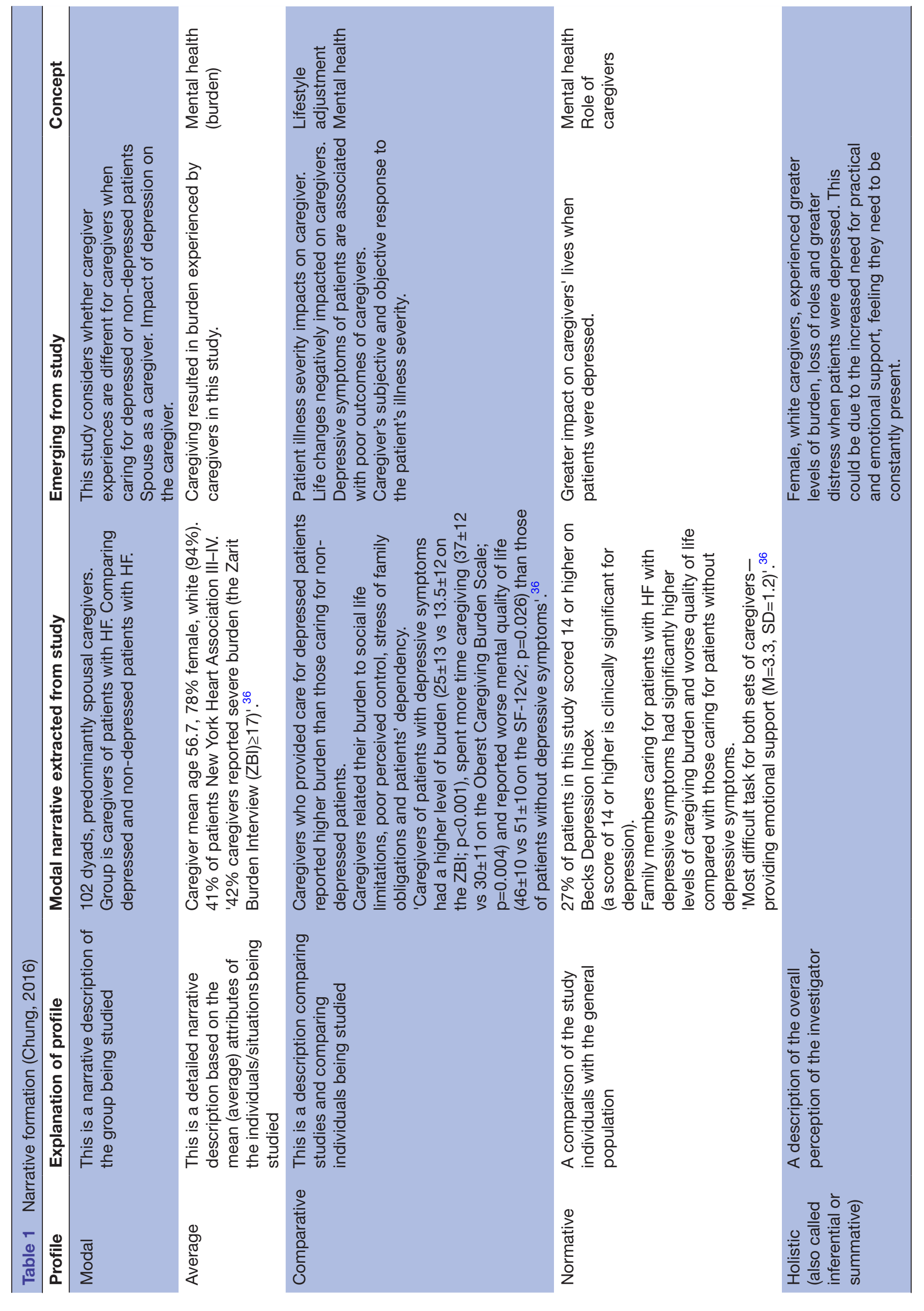




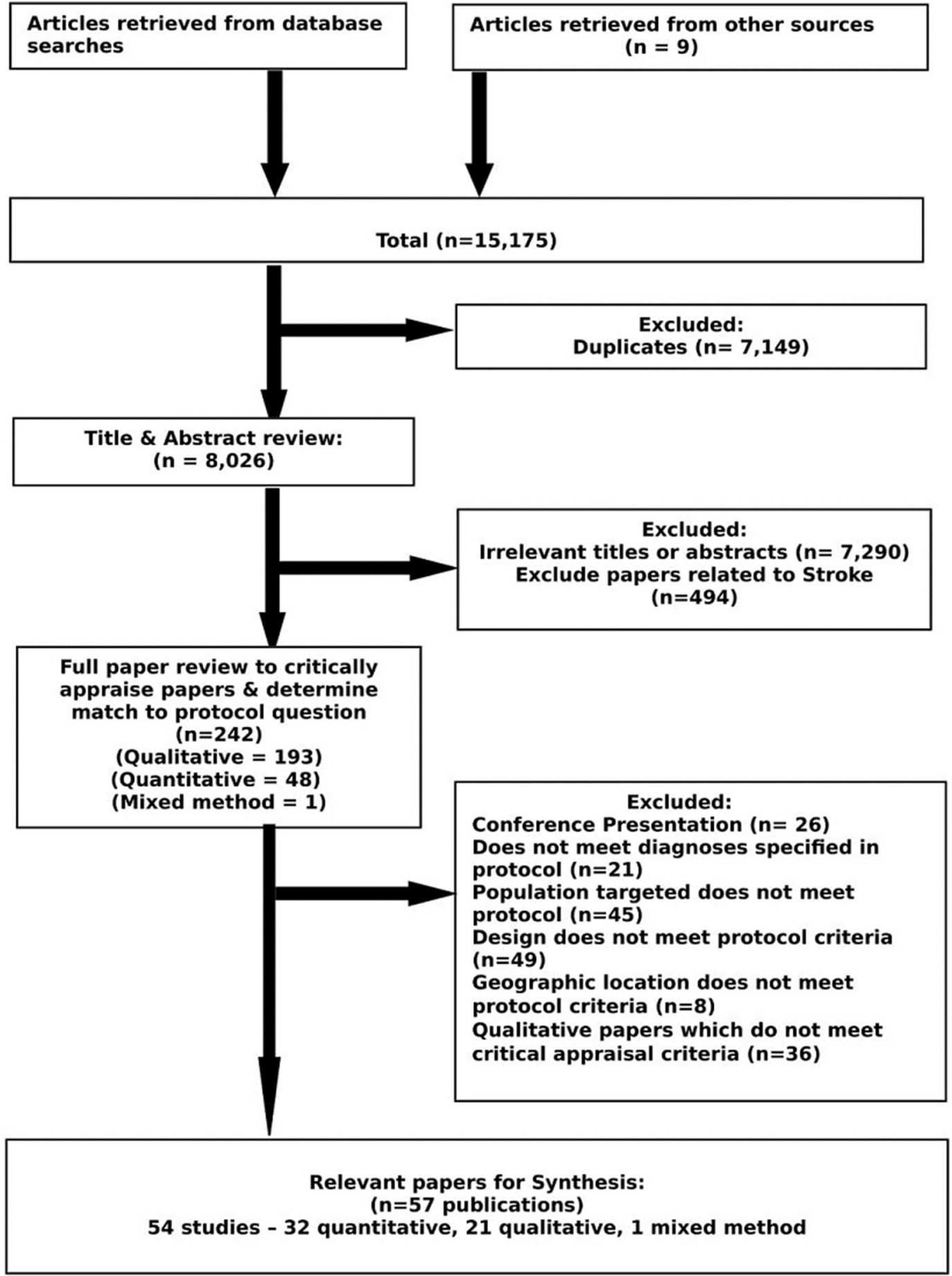

Figure 1 Preferred Reporting Items for Systematic Reviews and Meta-Analyses flow diagram.

\section{Caregiver role}

This is addressed in 18 qualitative ${ }^{64-72} 747577-8385$ and 14 quantitative studies. ${ }^{36}$ 39-41 49-51545759 60 86-89 Caregiver role is complex and requires much coordination. ${ }^{748183}$ Caregivers describe significant role change such as increasing domestic tasks. ${ }^{6366697176-7982}$ Role loss is prevalent ${ }^{646570}$ and caregivers need to reframe their identity. ${ }^{72} 80$ Societal expectation regarding the relationship and gender, influences caregivers adjusting to their roles. ${ }^{6567687479}$ Caring can be positive and rewarding. Caregivers learn about themselves and strengths they have. ${ }^{6575-77808183}$ Pressler et al described the tasks involved: domestic, emotional support, managing dietary needs and transport. ${ }^{54}$ Pressler et $a l$ also reported that caregivers of persons with greater HF symptoms experienced more difficulty with their role. $^{54}$

\section{Lifestyle changes}

Fourteen quantitative $3638-4043455254596062878890$ and 21 qualitative ${ }^{63-8385}$ studies addressed lifestyle changes. Caregivers experienced leisure, social and work-related problems. ${ }^{36} 3990$ Caring interrupted and eliminated 


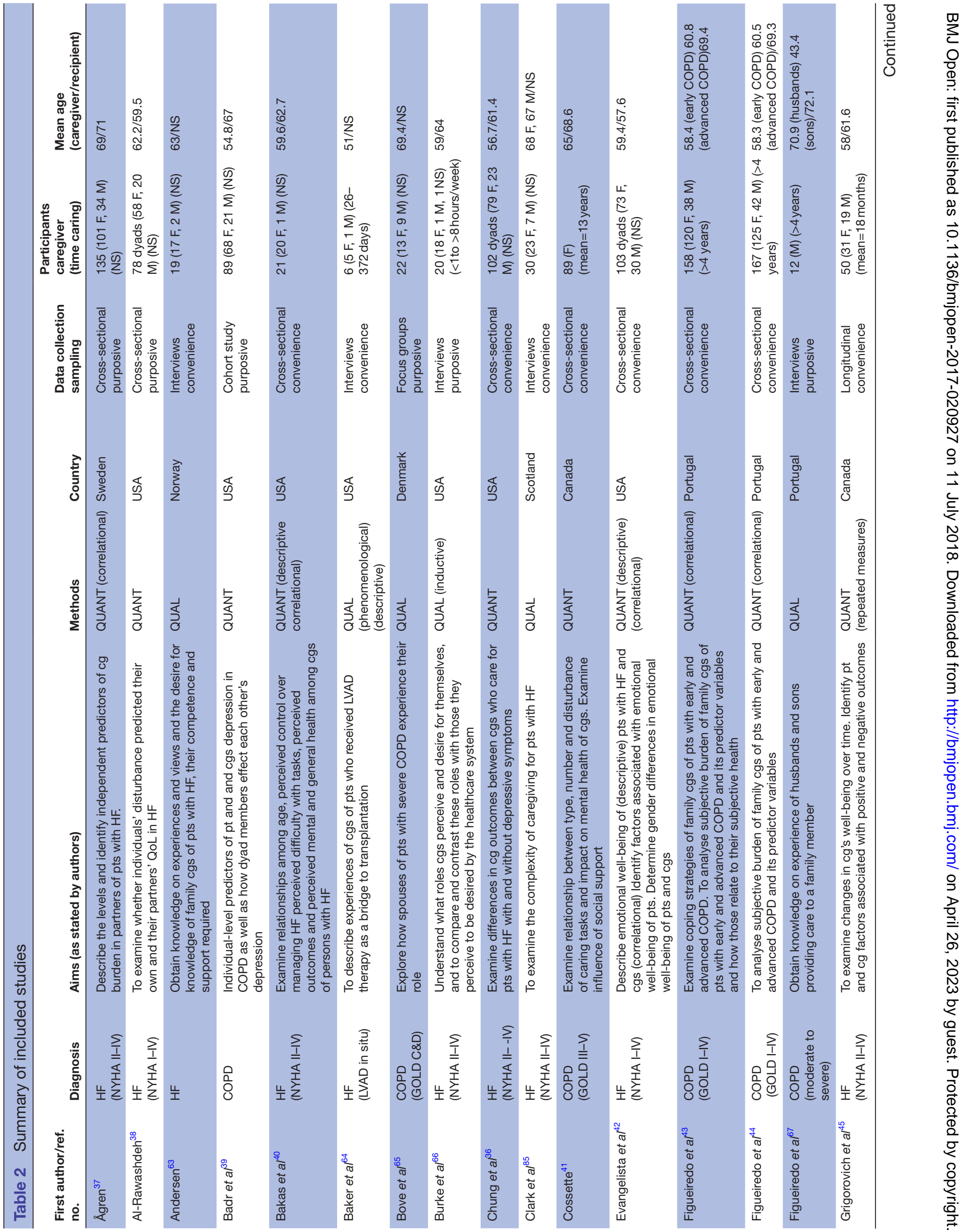




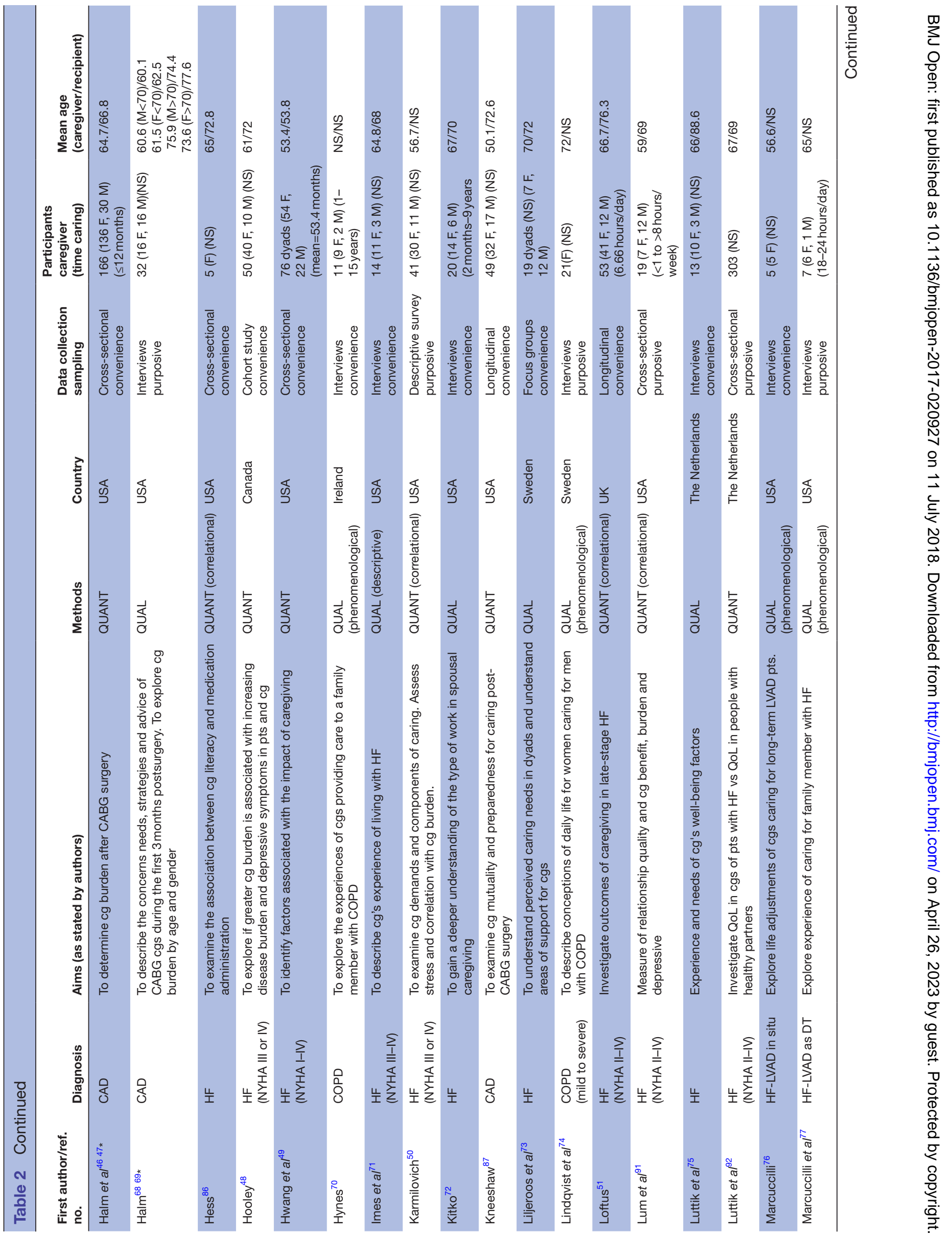




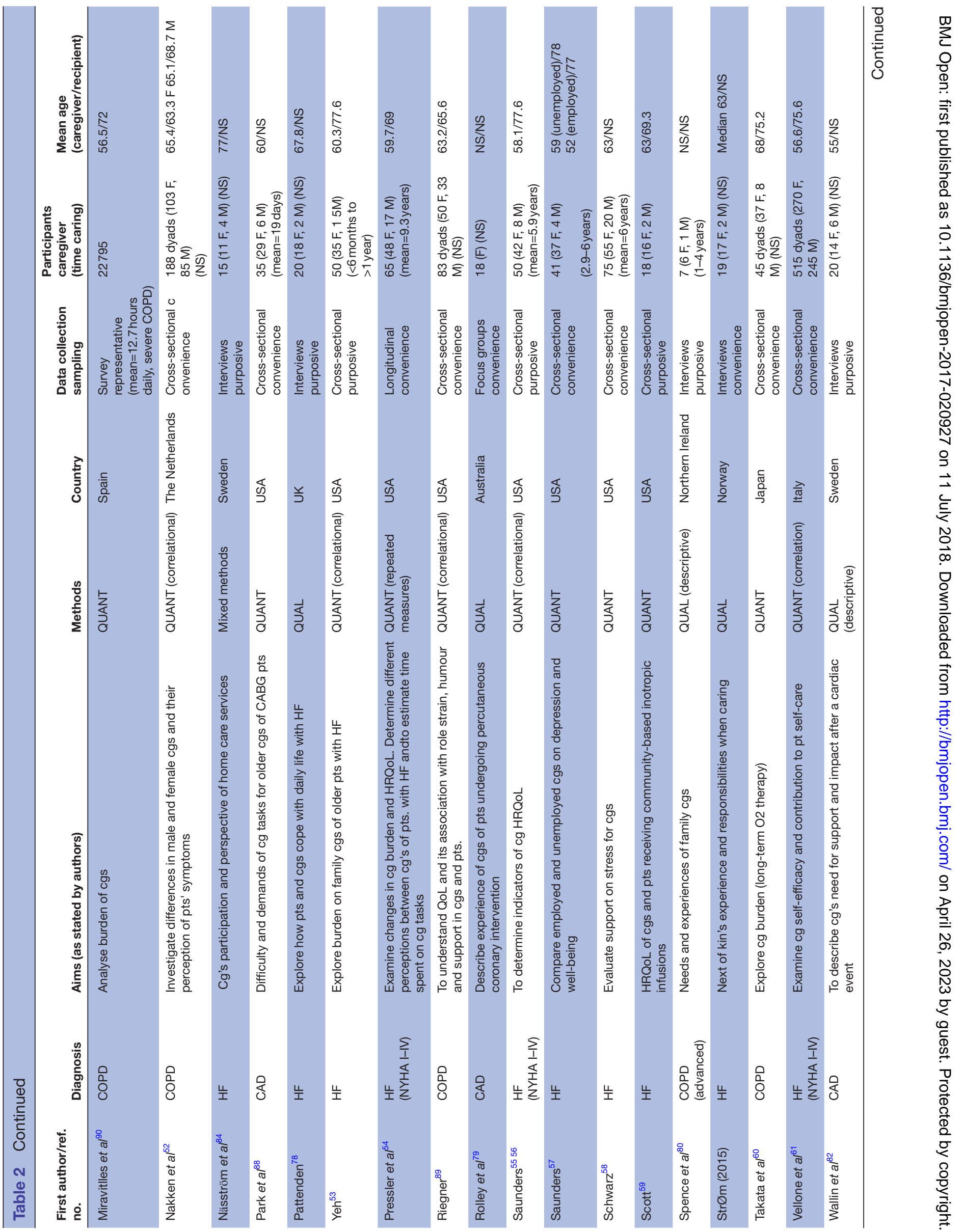


tasks from their routine. ${ }^{36} 3959$ Contrastingly, Pressler et al reported caregivers' perceptions of how their lives changed as a result of caregiving was neutral and improved from baseline to 4 and 8 months. ${ }^{54}$ Caregivers became adaptable in their new role. ${ }^{72} 8085$ There was less personal time for leisure and hobbies either alone or with the care recipient. ${ }^{67-70} 76778283$ Caregivers described daily 'ups and downs' and had to adjust their routines dependent on the presentation of the care recipient. 63646671737578798183

\section{Support for caregivers}

Fifteen quantitative, ${ }^{41}$ 45-47 49 51-53 55 5658-60 62878921 qualitative $^{63-83} 85$ and 1 mixed methods ${ }^{84}$ study examine support. This includes healthcare, family and social support. The weight of perceived external expectations, the necessity of being proactive in obtaining support and maintaining a social role was described across all diagnoses. ${ }^{45} 46$ 48-50 53-57 6189 Yeh and Bull identified lack of family support as a significant issue.$^{53}$ Caregivers felt abandoned by healthcare teams. After hospital discharge they had to provide care without advice or medical support. ${ }^{667278}$ Positive interactions were reported, namely access to healthcare professionals via telephone or home support. ${ }^{63647784}$

\section{Knowledge}

This was addressed in 17 qualitative, ${ }^{6365-75} 7779808283855$ quantitative ${ }^{506-6287}$ and 1 mixed methods ${ }^{84}$ study. This describes caregivers' understanding of the diagnosis and need for knowledge throughout the duration of illness. ${ }^{63} 677075$ 83-85 Caregivers report information from health professionals was often inadequate. ${ }^{7173}$ Timing and format of information was significant. Caregivers received information verbally or by leaflets in hospital but describe being left alone to provide care in the long term. ${ }^{65} 68697982$ Caregivers had difficulty understanding how to navigate the care system. ${ }^{72} 80$ They had to make decisions without full knowledge of the consequences of their decision making, particularly during acute exacerbations. ${ }^{65}$ The quantitative element of mixed methods study by Näsström et al correlated with qualitative studies; receipt of sufficient information was central to managing $\mathrm{HF}$ and was associated with better perceived health of caregivers. ${ }^{84}$

\section{Relationships}

Twenty qualitative, ${ }^{64-83} \quad 85 \quad 22$ quantitative $^{35373842-4446-5254-57618790-92}$ and 1 mixed methods ${ }^{84}$ study examined relationships. In HF studies caring for individuals with more symptoms resulted in poorer perceived experiences. ${ }^{5491}$ Higher relationship quality resulted in less burden and more benefit from the relationship. The relationship prior to diagnosis influenced the current relationship. Perspective of the relationship was either a sense of duty ${ }^{6574808184}$ or this was a valuable second chance. ${ }^{66758283}$ Caregivers reported difficulty communicating about the condition leading 
Table 3 Study characteristics

Summary of study characteristics

$\mathrm{n}=54$ studies

Aetiology of patients

$\begin{array}{ll}\text { CAD, } n(\%) & 6(11) \\ \text { HF, } n(\%) & 34(63) \\ \text { COPD, } n(\%) & 14(26)\end{array}$

Caregiver participants*

Patients $\dagger$

Median age (range)

$62(43-77)$

$69(36-93)$

Median \% of female (range)

$63 \%(5-270)$

$38 \%(1-229)$

Relationship between patient and caregiver ( $n=26008$ caregivers)

\begin{tabular}{|c|c|}
\hline Spousal/partner, n (\%) & $2321(9)$ \\
\hline Son/daughter, n (\%) & $610(2)$ \\
\hline Sibling, n (\%) & $22(<1)$ \\
\hline Parent, n (\%) & $10(<1)$ \\
\hline Friend/relative, $\mathrm{n}(\%)$ & $228(<1)$ \\
\hline Not stated & $22961(88)$ \\
\hline \multicolumn{2}{|l|}{ Type of study } \\
\hline Qualitative, n (\%) & $21(39)$ \\
\hline Quantitative, n (\%) & $32(59)$ \\
\hline Mixed & $1(2)$ \\
\hline \multicolumn{2}{|l|}{ Study design } \\
\hline Cross-sectional, n (\%) & $24(44)$ \\
\hline Longitudinal, n (\%) & $4(7)$ \\
\hline Cohort, n (\%) & $2(4)$ \\
\hline Quantitative (survey), n (\%) & $2(4)$ \\
\hline $\begin{array}{l}\text { Qualitative (interview/focus group), } \mathrm{n} \\
(\%)\end{array}$ & $16(31)$ \\
\hline Phenomenological, n (\%) & $5(8)$ \\
\hline Inductive, n (\%) & $1(2)$ \\
\hline \multicolumn{2}{|l|}{ Continents of publication } \\
\hline Europe & $22(41)$ \\
\hline North America, n (\%) & $29(54)$ \\
\hline Australasia, n (\%) & $3(5)$ \\
\hline Date of publication & $\mathrm{n}=57$ publications $\ddagger$ \\
\hline 1990-1995 & 2 \\
\hline 1996-2001 & 3 \\
\hline 2002-2007 & 10 \\
\hline 2008-2013 & 22 \\
\hline 2014-2017 & 20 \\
\hline
\end{tabular}

${ }^{*}$ Caregiver data based on data collected in 50 studies.

†Patient data based on data collected in 35 studies.

$\ddagger$ There were 57 publications, however there were 54 studies. The following studies used the same data but produced two publications: Halm, 2006 and 2007, Saunders, 2008 and 2009, Halm 2016 and 2017.

CAD, coronary artery disease; COPD, chronic obstructive pulmonary disease; $\mathrm{HF}$, heart failure.

to isolation, stress and conflict between caregiver and care recipient..$^{71}$ The relationship requires negotiation. ${ }^{69} 85$ Caregivers prioritised the care recipient over their own needs. ${ }^{64} 72747782$

\section{Expert by experience}

Twelve qualitative studies ${ }^{65-70} 72757680818385$ addressed this concept. Caregivers learnt new skills. They became 'experts by experience' discovering through 'doing' and 
Table 4 (a) Quality appraisal-qualitative papers

\begin{tabular}{|c|c|c|c|c|c|c|}
\hline First author/ref. no. & Design & Recruitment & Data collection & $\begin{array}{l}\text { Data } \\
\text { analysis }\end{array}$ & Findings & Total \\
\hline Andersen $^{63}$ & 1 & 1 & 1 & 0 & 1 & $4(\mathrm{H})$ \\
\hline Baker et al ${ }^{64}$ & 1 & 0 & 1 & 1 & 1 & $4(\mathrm{H})$ \\
\hline Bove et $a l^{65}$ & 1 & 1 & 1 & 1 & 1 & $5(\mathrm{H})$ \\
\hline Burke et al ${ }^{66}$ & 1 & 1 & 1 & 1 & 1 & $5(\mathrm{H})$ \\
\hline Halm $^{68 *}$ & 1 & 1 & 1 & 1 & 1 & $5(\mathrm{H})$ \\
\hline Halm $^{69 *}$ & 1 & 1 & 1 & 1 & 1 & $5(\mathrm{H})$ \\
\hline Hynes $^{70}$ & 1 & 1 & 1 & 0 & 1 & $4(\mathrm{H})$ \\
\hline Imes et $a l^{71}$ & 1 & 1 & 1 & 1 & 1 & $5(\mathrm{H})$ \\
\hline 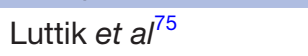 & 1 & 1 & 1 & 1 & 1 & $5(\mathrm{H})$ \\
\hline Marcuccilli $^{76}$ & 1 & 0 & 1 & 1 & 1 & $4(\mathrm{H})$ \\
\hline Marcuccilli $^{77}$ & 1 & 1 & 1 & 1 & 1 & $5(\mathrm{H})$ \\
\hline Näsström et $a l^{84} \dagger$ & 1 & 1 & 1 & 1 & 1 & $5(\mathrm{H})$ \\
\hline Pattenden $^{78}$ & 1 & 1 & 1 & 1 & 0 & $4(\mathrm{H})$ \\
\hline Rolley et $\mathrm{al}^{79}$ & 1 & 1 & 1 & 1 & 0 & $4(\mathrm{H})$ \\
\hline Spence et $a l^{80}$ & 1 & 0 & 1 & 1 & 1 & $4(\mathrm{H})$ \\
\hline Strøm (2015) & 1 & 1 & 1 & 1 & 1 & $5(H)$ \\
\hline
\end{tabular}

*Same study.

†Mixed methods study - qualitative component.

$\mathrm{H}$, high quality, $4 / 5$ out of 5 quality criteria achieved.

observing health professionals. ${ }^{66} 6883$ They developed 'proto-professional skills'; in medication administration $^{658085}$ judging care recipients' level of functioning ${ }^{79}$ and decision making in times of exacerbations. ${ }^{70}$ Caregivers observed the nuances of change in the care recipient often not perceived by healthcare teams or other family members such as skin colour or irritability. ${ }^{72} 7581$

\section{Vigilance}

Vigilance was recurring in caregivers' narrative across all diagnoses and was present in 19 qualitative studies. ${ }^{64-81} 8385$ Caregivers were always on the alert observing the care recipient. ${ }^{6677072-7477-7981}$ They lay awake at night listening for their partners' breath. ${ }^{69717585}$ This impacted on caregivers' health creating constant fatigue, worry and stress. ${ }^{65} 79$ Caregivers recognised that the need for vigilance came from themselves and their insecurities. ${ }^{64} 7683$

\section{Time}

Time explores how caregivers adjusted to living with the illness and was present in 15 qualitative studies. $^{65}$ 67-77 80828385 Caregivers adapted to a new life, referring to 'then', how life was and 'now' their current life. ${ }^{6970757683}$ The duration of caregiving and severity of illness influenced caregiver's ability to adjust. ${ }^{667376}$ Caregivers lived day by day ${ }^{83}$ and viewed the future, with hope or uncertainty about what lay ahead. ${ }^{6570727982}$

\section{Shared care}

Shared care was present in 16 qualitative studies. ${ }^{63-66} 68-7680818385$ This demonstrates caregiver and care recipient working together managing the illness, jointly administering medication ${ }^{68} 81$ and attending appointments. ${ }^{73}$ The presence of illness was a process they adjusted to together. ${ }^{7680}$ Caregivers referred to themselves and the care recipient as 'we', when discussing dealing with the illness. ${ }^{6371} 75$ The mutual perspective between caregiver and care recipient served to isolate them from the world, the illness was 'taking a life of its own... it's like this third person' (Hynes, 2012, p. 1071).

There were differences in caregiver experience for each of the diagnoses and these are discussed below.

\section{Heart failure}

HF caregivers experienced an 'ebb and flow' in caring, an underlying worry, fear and anxiety, which at times of 
Table 4 (b) Quality appraisal-quantitative papers

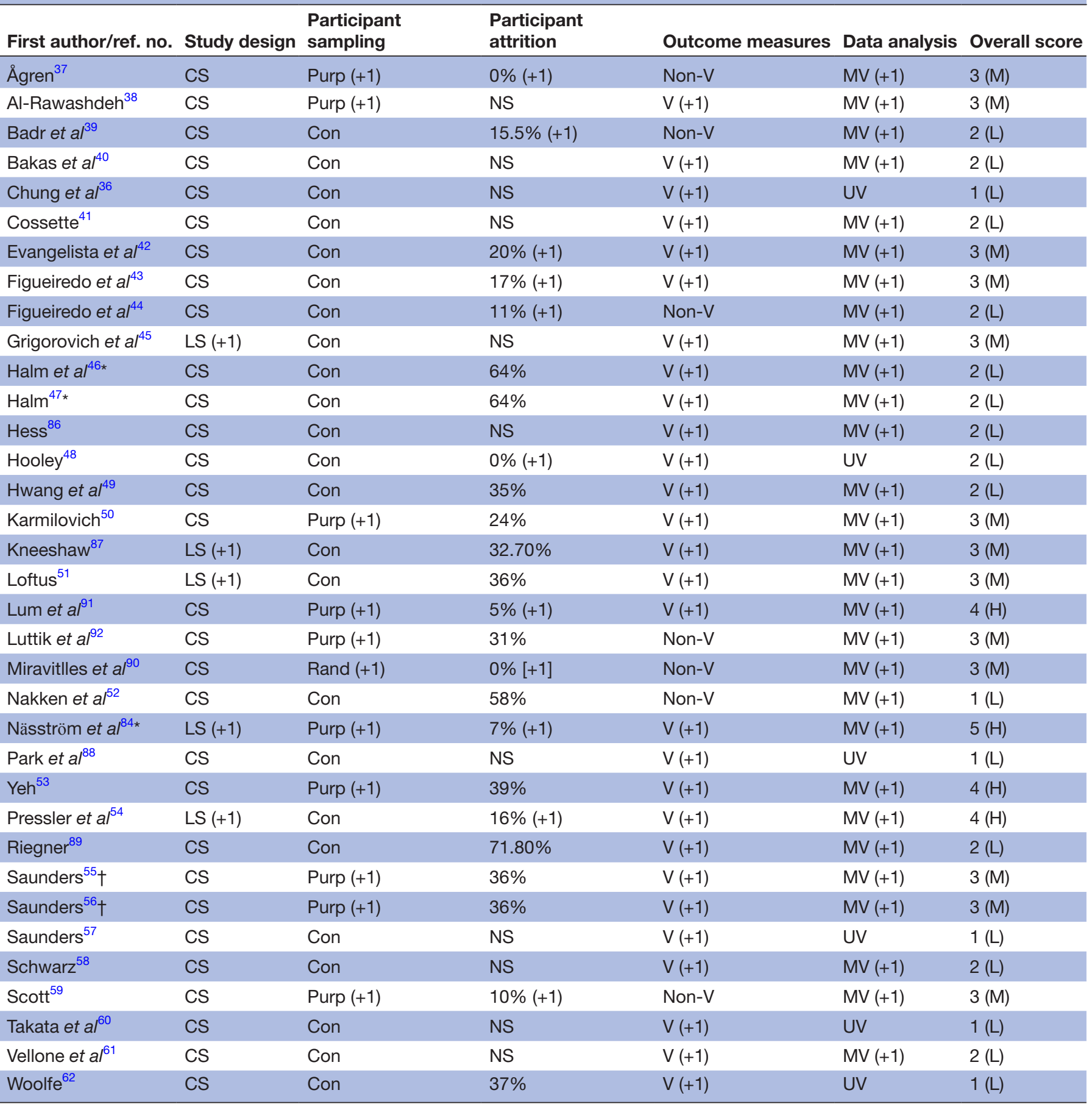

Studt design: CS, LS.

Participant sampling: Purp, Rand, Cons, Con, NS.

Attrition: $20 \%$ or less $=+1$; NS.

Outcome measures: V, non-V, NS.

Data analysis: MV, UV.

*Same study.

†Mixed methods study-quantitative component.

CS, cross-sectional design; Cons, consecutive; Con, convenience; $\mathrm{H}$, high quality, 4/ 5 out of 5 quality criteria achieved; L, low quality, 1 or 2 out of 5 quality criteria achieved; LS, longitudinal design; M, medium quality, 3 out of 5 quality criteria achieved; MV, multivariate; non-V, some or all non-validated; NS, not stated/unclear; Purp, purposive; Rand: random; V, all validated outcomes; UV, univariate.

change or illness heightened. ${ }^{49} 5159717781838592$ Lifestyle changes were long lasting and sustained. ${ }^{39} 5964717781838592$ Obtaining knowledge was necessary throughout all stages of the illness. ${ }^{50} 636673838592$ Sourcing information and communication with health professionals was often difficult. ${ }^{6366718592}$ In spousal relationships, they predominantly 


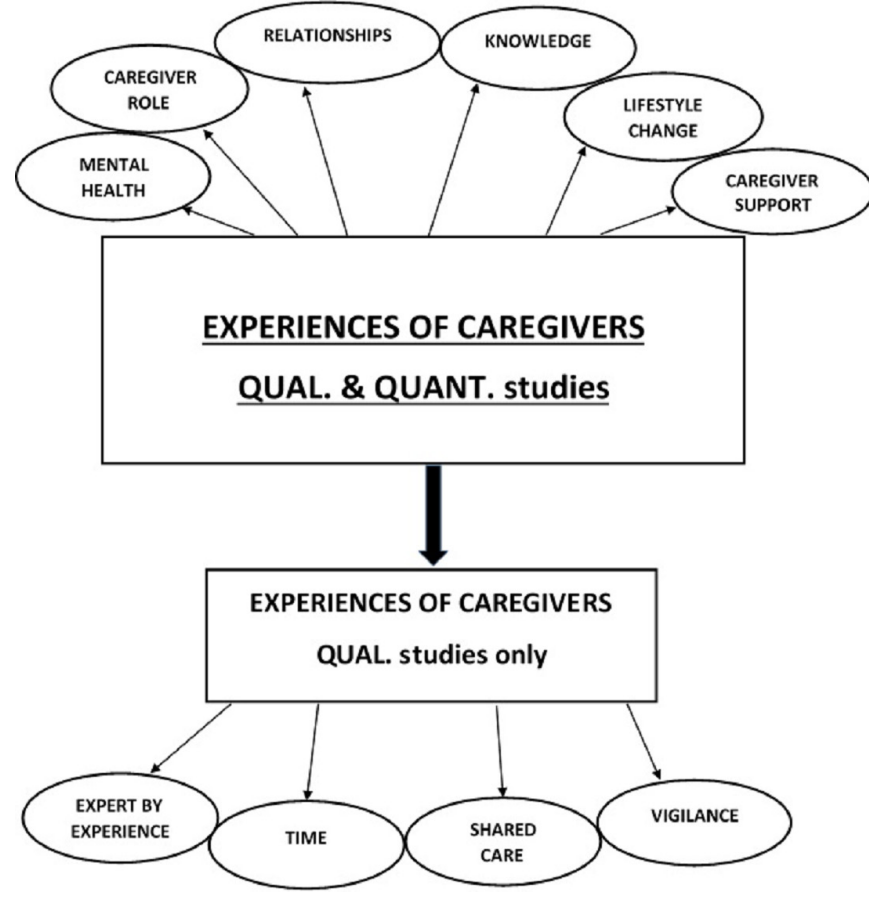

Figure 2 Conceptual experiences of caregivers.

viewed the care recipient as another child or as a 'duty'. 5051646671737784

\section{Chronic obstructive pulmonary disease}

COPD caregivers experienced a prolonged impact on their mental health similar to HF caregivers. 41445260657080 Severity of illness was influential on their experience of burden. ${ }^{38434460}$ Role change was long lasting and profound for many. ${ }^{65677080}$ They expressed concerns with perceived lack of knowledge. ${ }^{62} 65707480$ During exacerbations, COPD caregivers experienced anxiety and fear of their loved one dying. ${ }^{65677074}$ COPD caregivers highlighted the loss of social roles while trying to maintain the dignity of their loved ones. 657074808990 The coughing and spitting associated with COPD often left the care recipient embarrassed. ${ }^{656780}$ The caregiver tried to avoid situations where this would happen. The dynamics of spousal relationships changed, caregivers described losing the intimate love they had for their partner. ${ }^{65} 707480$

\section{Coronary artery disease}

Caregivers of patients with CAD experienced intense role change on discharge from hospital and in the acute phase of illness. ${ }^{476879828788}$ They initially engaged with a high volume of tasks which reduced over time. 46476879828788 CAD caregivers experienced post-traumatic symptoms if they witnessed the recipient experience an acute event. ${ }^{79}$ Caregivers described being unable to talk about this and reliving the event in their heads. Anxiety did ease over time for many. ${ }^{79}$ Caregivers felt unprepared at hospital discharge and highlighted not realising how much their routine would be disrupted. ${ }^{68} 7982$ Caregivers reported viewing the experience as a second chance and had a renewed sense of love and appreciation for the relationship. ${ }^{79} 82$

\section{DISCUSSION}

This mixed methods systematic review demonstrates the similarities and differences in caregiver experiences across three common cardiorespiratory conditions. It highlighted the differences in experiences obtained from qualitative and quantitative research. Commonly occurring experiences included the exacerbation of caregiver physical and mental health due to the role. This correlates with systematic review of HF caregivers by Kang et al identifying that caregiving resulted in a multitude of changes in caregiver's lives regardless of age, gender and ethnicity. ${ }^{93}$ Addressing both patient and caregiver needs in order to maintain well-being for both is important ${ }^{19}$ and recognises the value of 'shared-care' between patient and caregiver. The prevalence of mental health needs in this review demonstrates the need for psychosocial support for caregivers. This concurs with the studies by Aasb $\varnothing$ et al, identifying caregivers need to be in 'emotional control' $^{\text {'94 }}$ and Wingham et al, describing the 'enduring anguish' experienced by caregivers. ${ }^{95}$ Lawton et al attribute caregiver well-being to the commitment of the caregiver to the role and dealing with competing demands, which can increase burden and negatively impact affect. Spousal caregivers may be more ready to accept the role of caregiving than adult children who may view it as an imposition on an already established lifestyle. ${ }^{96}$ In this review, societal expectations had an impact on how caregivers adjust to their role. Additionally, the quality of the relationship prior to becoming a caregiver had an influence on the caregiver subjective experience of burden.

Caregivers had predominantly negative experiences of support and described uncertainty of how to obtain this. Caregivers need greater support and knowledge transfer to conduct their role. ${ }^{97}$ They should be included in clinical appointments ${ }^{98}$ to ensure they are not isolated in providing care and to allow for knowledge exchange. Giacomini et al in their review of caregivers living and dying with COPD reported increasing isolation in addition to their own health issues. ${ }^{18}$ They described pressure balancing their variety of roles; similar experiences to the caregivers in this synthesis across all diagnoses. Caregivers emphasised their need to be vigilant. This falls into five categories as defined by Mahoney's study of Alzheimer's caregivers; 'watchful supervision', 'protective intervening', 'anticipating', 'on duty' and 'being there'. Caregivers in this synthesis described overt vigilance, putting one's head on the chest of the recipient to check breathing or covert vigilance; observing them throughout the day. ${ }^{99}$ Healthcare professionals must be aware of these levels of vigilance and the constant presence of them to support caregivers in their role.

Caregivers are valuable providers of care. Caregiver's needs should be assessed systematically and in a formalised manner in healthcare settings. ${ }^{16}$ When 
Table 5 Illustrative quotes of caregiver experience-by concept

Mental health "The mental strain is difficult. I feel so trapped".

"You fall into a huge hole, then the world gets so tiny, it all gets sonarrow that it is almost unbearable".

"I feel like sleeping beauty. The hawthorn hedge has closed around me, and I cannot do anything about it.".

Role "I can sum my role up in three words, I am a cheerleader, drill sergeant, and negotiator".

Lifestyle change "Our life has come down. The two of us used to go out dancing. We loved dancing and then it all stopped".

Knowledge "I wish I had had more education on the 'what ifs'. When I was leaving the hospital nobody really said, 'OK now this is what's going to happen and this is what you're going to have to do'. If there would've been any kind of complications I would've been totally in the dark. I didn't know all the things I needed to know".

Relationships "I just love him and I find that every day when I see him, what else could I do to try and make him a wee bit ... better? It's very satisfying to know that he appreciates what I do and it's nice to know that you are helping someone".

"It's like having another child sometimes because you are sort of responsible and I feel he is my responsibility. I feel that he is not anybody else's responsibility..."

Support "And then I really felt alone in it all. Because everybody would call and come over and ask, how is
John? Hardly anyone asked 'how are you doing'"?
"Doctors (do) not realize that 1 day your life is jut normal and then this comes and smashes everything
to bits, you know and there are so many questions".
"I would be lost without, our heart failure nurse, and, all the other input we've had from all the other
professionals, like the podiatrist and GP... You can do it, but in partnership with everybody else".

Vigilance "Every morning I put my ear to his chest and listen to his heart, that is how we first discovered he was in atrial fibrillation so now I do it every morning before I leave. I monitor him very closely and there are days in which I do not feel comfortable leaving for work so those days I work at home. I call everyday from work and we have our routine, if I am not aware of anything he had planned for the day, I then immediately call my neighbour to check on him".

Shared care
"There were days I thought to myself, where are we going from here? But we mastered it together and
tried to do things at his pace".
"At first it was overwhelming. I didn't think I could do it. When they first told me I was like, 'I can't do
that', you know. And then they explained to me, like, yes you can. It's like getting a new baby. You
know, you learn how to take care of them step by step and then it's just part of the routine. And that's
really the way it was".

developing collaborative models of care the inclusion of caregivers is imperative. ${ }^{100}$

\section{Strengths and limitations}

This review demonstrates the complexity of what it means to be a caregiver and should inform clinical care development of interventions. A mixed methods review can be contentious ${ }^{101}$ due to the synthesis of differing paradigms. In this review, it required transformation of quantitative data into qualitative data. ${ }^{15} 102$ We aimed to present a convergence of caregiver experiences by conducting a mixed methods synthesis. However, it demonstrated four differing concepts between the two paradigms. This highlights the challenge of synthesising multiple methods. It is worth exploring how the four additional qualitative concepts could be captured quantitatively in order to inform healthcare intervention. This mixed methods synthesis is, to our knowledge, the first to combine caregiver experiences in HF, COPD or CAD. It examines the differences and similarities in experiences, establishing a comprehensive assessment of the knowledge base of caregiver experiences in common cardiorespiratory conditions.

There are limitations to this study; both in our review methods and the nature of included studies. First, we acknowledge that the inclusion of lower quality quantitative studies may lead to risk of bias: the majority of quantitative studies used convenience sampling, had a high attrition and low response rate. Non-validated outcome measures were used in some quantitative studies with the majority of studies conducting univariate rather than multivariate analysis. However, given the limited number of high-quality quantitative studies (four studies), we believe this broader inclusion increased the scope of our review in order to achieve a holistic understanding of 
caregiver experiences. Furthermore, we would note that the conclusions of this review were broadly the same with consideration of only the high-quality quantitative studies. Second, studies were restricted to English language only, from high-income countries and excluding caregivers of nursing home residents. This may limit the applicability of findings to other settings. Third, converting quantitative data into a qualitative data set risks the quantitative data set being oversimplified. This was managed with regular research team meetings to review each stage of this process. Fourth, qualitative synthesis is an interpretation of other researcher's interpretations. To minimise individual interpretative bias, a second researcher was used to seek confirmation of the results. Finally, included qualitative and quantitative studies were primarily cross-sectional in design, therefore considering caregiver experience only at a single point of time.

\section{Implications for practice and future research}

There are a number implications following this review. It has demonstrated there are similarities and differences in the caregiver experience in HF, COPD or CAD. The impact on caregiver's lives of those with HF and COPD appears longer lasting and more turbulent than caring for patients with CAD. CAD caregiver's experience of hospital during exacerbations increased distress at discharge. This review reflects the complexity of the caregiver's role. The mixed methods approach indicted differences in what is being investigated. This is important in demonstrating an understanding of the caregiver experience when dealing with complex conditions. Future research should focus on involving caregivers in the design and delivery of interventions for patients with cardiopulmonary disease. Best practice interventions for $\mathrm{CAD}$ caregivers in the discharge process from hospital to home must be formalised. There appears to be a focus on the mental health of caregivers of those with HF; however, further research is needed to explore this in COPD and CAD caregivers. Exploration of this via support groups for caregivers of cardiorespiratory conditions is merited. Clinically, the healthcare team need to identify who the caregiver is and be aware of their needs with the use of a carer's needs assessment. There must be a greater understanding of caregiver support needs, what they avail of and are they aware of what is available to them in the community. This can be achieved in conversation between the healthcare team and caregivers and warrants further research as to how and whether caregivers avail of external supports.

Consideration needs to be given as to whether quantitative research tools to explore caregiver expertise, view of the future, experience of shared care and vigilance can be developed to capture these qualitative concepts to inform the development of self-management interventions for patients and caregivers. Repeated measures examining perceived control and caregiver needs may contribute to a greater understanding of caregiver experiences, which arose in qualitative studies. Additionally, longitudinal studies with repeated assessment need to be conducted to assess the stability of caregiver experiences and whether they are liable to much change over time. In this review, only 4 out of 32 quantitative studies examined caregiver's experiences longitudinally. Understanding whether there are caregiver changes over time will facilitate greater understanding of caregiver needs for health professionals when working with this population. The emergence of additional concepts from qualitative studies emphasises the role of mixed methods research when examining lived experiences. The additional concepts also demonstrated the nuanced expertise of the caregiving experience. It is important for researchers to consider how to reflect this in quantitative investigation so as to inform funders in order to develop and trial interventions in HF, COPD and CAD. The quality of quantitative studies in COPD and CAD were medium or low. There is a need for more empirically robust studies examining the experiences of these caregivers. Additionally, greater understanding of caregiver's experiences with this population will facilitate the development of robust evidence-based guidelines for health services when working with HF, COPD and CAD.

\section{CONCLUSIONS}

This mixed methods systematic review provides a holistic synthesis of caregiver experiences of people with HF, COPD or CAD. It demonstrates there are a number of implications when an individual becomes a caregiver for those with chronic cardiopulmonary disease. Caregivers reframe their identity and change their life course. Caregivers learn a multitude of skills and develop expertise in their new role. Their expertise is invaluable and should be acknowledged in healthcare interventions for these conditions. The quality of evidence was limited by assessment of caregiver experience at single time point. There is need for future studies that employ longitudinal designs examining the change in caregiver experience over time. Caregiving can be positive if caregivers have access to support, are well informed and part of the healthcare team. Understanding the experiences of caregivers for people with these conditions allows healthcare professionals and policy makers to reflect on our approach. Health services must consider caregivers in the design and delivery of interventions.

\section{Acknowledgements The authors would like to thank the PenCLARHC Evidence Synthesis Team at University of Exeter Medical School. Katy Oaks and Catriona Organ, Librarians at Royal Cornwall Hospital Library, Knowledge Spa, Truro. Dr Ruth Garside, Senior Lecturer in Evidence Synthesis, European Centre for Environment and Human Health for their assistance throughout the process of this review.}

Contributors MN, JW, RST: conceived and designed the review and quality appraised the included studies. MN wrote the initial draft of the manuscript. JW and RST provided feedback and edits to manuscript drafts.

Funding This study was supported by a University of Exeter Postgraduate Studentship Grant.

Competing interests None declared.

Patient consent Not required.

Provenance and peer review Not commissioned; externally peer reviewed. 
Data sharing statement Any requests for additional information about the study can be accessed via contacting the primary author.

Open access This is an open access article distributed in accordance with the Creative Commons Attribution 4.0 Unported (CC BY 4.0) license, which permits others to copy, redistribute, remix, transform and build upon this work for any purpose, provided the original work is properly cited, a link to the licence is given, and indication of whether changes were made. See: https://creativecommons.org/ licenses/by/4.0/.

\section{REFERENCES}

1. . Carers Trust (2015)https://carers.org/what-carer (accessed 26 June 2017)

2. Wolff JL, Spillman BC, Freedman VA, et al. A National Profile of Family and Unpaid Caregivers Who Assist Older Adults With Health Care Activities. JAMA Intern Med 2016;176:372-9.

3. International Alliance of Carer Organizations. Global carer facts. 2017 http://www.internationalcarers.org/carer-facts/global-carerstats/ (accessed1 Oct 2017).

4. White C. Census Analysis: Unpaid care in England and Wales, 2011 and comparison with 2001. Office of National Statistics. 2013 https://www.ons.gov.uk/peoplepopulationandcommunity/ healthandsocialcare/healthcaresystem/articles/2011censusanalys isunpaidcareinenglandandwales2011andcomparisonwith2001/ 2013-02-15 (accessed 10 Oct 2017).

5. Buckner L, Yeandle S, Carers V. Carers UK. The rising value of carers' support. 2015 http://www.carersuk.org/for-professionals/ policy/policy-library/valuing-carers-2015 (accessed July 2017).

6. The Institute of Public Care. A Carer's Life: Implications and Considerations for Commissioning. 2017 http://ipc.brookes.ac.uk/ publications/A_carers_life.html (accessed 30 Sep 2017).

7. Seltzer MM, Li LW. The dynamics of caregiving: transitions during a three-year prospective study. Gerontologist 2000;40:165-78.

8. The Care Act. Chapter 23. The Care Act UK: The Stationery Office, 2014. http://www.legislation.gov.uk/ukpga/2014/23/contents. enacted/data.htm. (accessed 11 Oct 2016).

9. National Institute for Health and Clinical Excellence. Chronic heart failure in adults: management: NICE guideline (CG108), 2010.

10. National Institute for Health and Clinical Excellence. Chronic obstructive pulmonary disease in over 16s: diagnosis and management: NICE guideline (CG101), 2010.

11. Wilkins E, Wilson L, Wickramasinghe K, et al. European Cardiovascular Disease Statistics 2017. Brussels: European Heart Network. http://www.ehnheart.org/images/CVD-statistics-reportAugust-2017.pdf. (accessed 25 Aug 2017).

12. Center for Disease Control and Prevention. Heart Disease Facts and Statistics. www.cdc.gov (accessed 9 Nov 2016).

13. Raherison C, Girodet P-O. Epidemiology of COPD. European Respiratory Review 2009;18:213-21.

14. Nicholas Dionne-Odom J, Hooker SA, Bekelman D, et al. Heart Fail Rev 2017;22:543.

15. Foster F, Piggott R, Teece $L$, et al. Patients with COPD tell their stories about living with the long-term condition: an innovative and powerful way to impact primary health care professionals' attitudes and behaviour? Educ Prim Care 2016;27:314-9.

16. Farquhar M. Assessing carer needs in chronic obstructive pulmonary disease. Chron Respir Dis 2018:15:1-10.

17. Mansfield E, Bryant J, Regan T, et al. Burden and Unmet Needs of Caregivers of Chronic Obstructive Pulmonary Disease Patients: A Systematic Review of the Volume and Focus of Research Output. COPD 2016;13:662-7.

18. Giacomini $M$, DeJean $D$, Simeonov $D$, et al. Experiences of living and dying with COPD: a systematic review and synthesis of the qualitative empirical literature. Ont Health Technol Assess Ser 2012;12:1-47.

19. Doherty LC, Fitzsimons D, Mcllfatrick SJ. Carers' needs in advanced heart failure: A systematic narrative review. Eur $J$ Cardiovasc Nurs 2016:15:203-12.

20. Stewart M, Davidson K, Meade D, et al. Myocardial infarction: survivors' and spouses' stress, coping, and support. J Adv Nurs 2000;31:1351-60.

21. Stolarik A, Lindsay $P$, Sherrard $H$, et al. Determination of the burden of care in families of cardiac surgery patients. Prog Cardiovasc Nurs 2000;15:4-10.

22. Falk JA, Kadiev S, Criner GJ, et al. Cardiac Disease in Chronic Obstructive Pulmonary Disease. Proc Am Thorac Soc 2008;5:543-8.
23. Müllerova H, Mapel DW. Cardiovascular comorbidity in COPD systematic literature review. CHEST 2013;144:1163-78.

24. Moher D, Liberati A, Tetzlaff J, et al. Preferred reporting items for systematic reviews and meta-analyses: The PRISMA statement. PLoS Med 2009;6(7.

25. Johnson RB, Onwuegbuzie AJ, Turner LA. Toward a Definition of Mixed Methods Research. J Mix Methods Res 2007;1:112-33.

26. . World Bank Data: http://www.worldbank.org/ (accessed 10 Jun 2017).

27. Critical Appraisal Skills Programme. Qualitative research checklist. http://docs.wixstatic.com/ugd/dded87_25658615020e427da194 a325e7773d42.pdf (accessed 10 Dec 2016).

28. Sandelowski M, Voils $\mathrm{Cl}$, Barroso J. Defining and Designing Mixed Research Synthesis Studies. Res Sch 2006;13:1-15.

29. Pluye P, Hong QN. Annual Review of Public Health. 2014 www. annualreviews.org (accessed 27 Sep 2016).

30. Hong QN, Pluye P, Bujold M, et al. Convergent and sequential synthesis designs: implications for conducting and reporting systematic reviews of qualitative and quantitative evidence. Syst Rev 2017;6:61.

31. Tashakkori A, Teddlie C. Mixed Methodology: Combining Qualitative and Quantitative Approaches. In:Applied Social Research Methods Series. Thousand Oaks, CA: SAGE Publications, 1998:46.

32. Noblit GW, Hare RD. Meta-ethnography: synthesizing qualitative studies. Thousand Oaks, CA: SAGE Publications, 1988.

33. Tashakkori A, Teddlie C. Foundations of Mixed Methods Research: integrating quantitative and qualitative approaches in the social and behavioural sciences. Thousand Oaks, CA: SAGE Publications, 2009.

34. Frantzen KK, Fetters MD. Meta-integration for synthesizing data in a systematic mixed studies review: insights from research on autism spectrum disorder. Qual Quant 2016:50:2251-77.

35. Dixon-Woods M, Fitzpatrick R, Roberts K. Including qualitative research in systematic reviews: opportunities and problems. J Eval Clin Pract 2001;7:125-33.

36. Chung ML, Lennie TA, Mudd-Martin G, et al. Depressive symptoms in patients with heart failure negatively affect family caregiver outcomes and quality of life. Eur $J$ Cardiovasc Nurs 2016;15:30-8.

37. Agren S, Evangelista L, Strömberg A. Do partners of patients with chronic heart failure experience caregiver burden? Eur J Cardiovasc Nurs 2010;9:254-62.

38. Al-Rawashdeh SY, Lennie TA, Chung ML. The Association of Sleep Disturbances With Quality of Life in Heart Failure Patient-Caregiver Dyads. West J Nurs Res 2017;39:492-506.

39. Badr H, Federman AD, Wolf M, et al. Depression in individuals with chronic obstructive pulmonary disease and their informal caregivers. Aging Ment Health 2017;21:975-82.

40. Bakas T, Pressler SJ, Johnson EA, et al. Family caregiving in heart failure. Nurs Res 2006;55:180-8.

41. Cossette $\mathrm{S}$, Lévesque L. Caregiving tasks as predictors of mental health of wife caregivers of men with chronic obstructive pulmonary disease. Res Nurs Health 1993;16:251-63.

42. Evangelista LS, Dracup K, Doering L, et al. Emotional well-being of heart failure patients and their caregivers. $J$ Card Fail 2002;8:300-5.

43. Figueiredo D, Gabriel R, Jácome $\mathrm{C}$, et al. Caring for people with early and advanced chronic obstructive pulmonary disease: how do family carers cope? J Clin Nurs 2013;23:211-20.

44. Figueiredo D, Gabriel R, Jácome C, et al. Caring for relatives with chronic obstructive pulmonary disease: how does the disease severity impact on family carers? Aging Ment Health 2014;18:385-93.

45. Grigorovich $\mathrm{A}$, Lee $\mathrm{A}$, Ross $\mathrm{H}$, et al. A longitudinal view of factors that influence the emotional well-being of family caregivers to individuals with heart failure. Aging Ment Health 2017;21:844-50.

46. Halm MA, Treat-Jacobson D, Lindquist $R$, et al. Correlates of caregiver burden after coronary artery bypass surgery. Nurs Res 2006;55:426-36.

47. Halm MA, Bakas T. Factors associated with caregiver depressive symptoms, outcomes, and perceived physical health after coronary artery bypass surgery. J Cardiovasc Nurs 2007;22:508-15.

48. Hooley PJ, Butler G, Howlett JG. The relationship of quality of life, depression, and caregiver burden in outpatients with congestive heart failure. Congest Heart Fail 2005;11:303-10.

49. Hwang B, Fleischmann KE, Howie-Esquivel J, et al. Caregiving for patients with heart failure: impact on patients' families. Am J Crit Care 2011;20:431-42.

50. Karmilovich SE. Burden and stress associated with spousal caregiving for individuals with heart failure. Progress in Cardiovascular Nursing 1994;9:33-8. 
51. Loftus L. The influence of illness and psychological factors on patient and caregiver outcomes in heart failure. PhD. University of Liverpool: Liverpool, 2004

52. Nakken $\mathrm{N}$, Janssen DJ, van Vliet M, et al. Gender differences in partners of patients with COPD and their perceptions about the patients. Int J Chron Obstruct Pulmon Dis 2017;12:95-104.

53. Yeh PM, Bull M. Use of the resiliency model of family stress, adjustment and adaptation in the analysis of family caregiver reaction among families of older people with congestive heart failure. Int J Older People Nurs 2012;7:117-26.

54. Pressler SJ, Gradus-Pizlo I, Chubinski SD, et al. Family caregivers of patients with heart failure: a longitudinal study. J Cardiovasc Nurs 2013;28:417-28.

55. Saunders MM. Factors Associated with Caregiver Burden in Heart Failure Family Caregivers. West J Nurs Res 2008;30:943-59.

56. Saunders MM. Indicators of health-related quality of life in heart failure family caregivers. J Community Health Nurs 2009;26:173-82.

57. Saunders MM. Working and caregiving a comparison of employed and unemployed caregivers of older heart failure patients. Holistic Nursing Practice 2010;24:16-22.

58. Schwarz KA, Dunphy G. An examination of perceived stress in family caregivers of older adults with heart failure. Exp Aging Res 2003;29:221-35.

59. Scott LD. Caregiving and care receiving among a technologically dependent heart failure population. ANS Adv Nurs Sci 2000;23:82-97.

60. Takata S, Washio M, Moriwaki A, et al. Burden among caregivers of patients with chronic obstructive pulmonary disease with long-term oxygen therapy. International Medical Journal 2008;15:53-7.

61. Vellone E, D'Agostino F, Buck HG, et al. The key role of caregiver confidence in the caregiver's contribution to self-care in adults with heart failure. European Journal of Cardiovascular Nursing 2015;14:372-81.

62. Woolfe P, McMillan M, Conway J. The needs of caregivers of people with COPD: a study. Australian Journal of Primary Health 2007;13:28-35.

63. Andersen KL, Korneliussen K, Fagermoen MS. Family caregivers to a patient with chronic heart failure living at home: "co-workers" in a blurred health care system. Journal of Cardiovascular Nursing 2015;20:162-9.

64. Baker K, Flattery M, Salyer J, et al. Caregiving for patients requiring left ventricular assistance device support. Heart Lung 2010;39:196-200.

65. Bove DG, Zakrisson A-B, Midtgaard J, et al. Undefined and unpredictable responsibility: a focus group study of the experiences of informal caregiver spouses of patients with severe COPD. J Clin Nurs 2016;25:483-93.

66. Burke RE, Jones J, Ho PM, et al. Caregivers' perceived roles in caring for patients with heart failure: what do clinicians need to know? J Card Fail 2014;20:731-8.

67. Figueiredo D, Jácome C, Gabriel R, et al. Family care in chronic obstructive pulmonary disease: what happens when the carer is a man? Scand J Caring Sci 2016;30:721-30.

68. Halm MA. Specific needs, concerns, strategies and advice of caregivers after coronary artery bypass surgery. Heart Lung 2016;45:416-22.

69. Halm MA. Age and gender influences on the needs, concerns and strategies of CABG caregivers. Heart Lung 2017;46:159-65.

70. Hynes G, Stokes A, McCarron M. Informal care-giving in advanced chronic obstructive pulmonary disease: lay knowledge and experience. J Clin Nurs 2012;21:1068-77.

71. Imes C, Dougherty CM, Pyper G, et al. Care of Patients with Heart Failure Descriptive study of partners' experiences of living with severe heart failure. Heart \& Lung 2011;40:208-16.

72. Kitko LA. The work of spousal caregiving in heart failure. State College, PA: Pennsylvania State University, 2010.

73. Liljeroos M, Ågren S, Jaarsma T, et al. Perceived caring needs in patient-partner dyads affected by heart failure: A qualitative study. $J$ Clin Nurs 2014;23:2928-38.

74. Lindqvist $\mathrm{G}$, Albin B, Heikkilä K, et a/Conceptions of daily life in women living with a man suffering from chronic obstructive pulmonary disease. Prim Health Care Res Dev 2013;14:40-51.

75. Luttik ML, Blaauwbroek A, Dijker A, et al. Living with heart failure: partner perspectives. J Cardiovasc Nurs 2007;22:131-7.

76. Marcuccilli L, Casida JM. From insiders' perspectives: adjusting to caregiving for patients with left ventricular assist devices. Prog Transplant 2011;21:137-43.
77. Marcuccilli L, Casida JJ, Bakas T, et al. Family caregivers' inside perspectives: caring for an adult with a left ventricular assist device as a destination therapy. Prog Transplant 2014;24:332-40.

78. Pattenden JF, Roberts H, Lewin RJ. Living with heart failure; patient and carer perspectives. Eur J Cardiovasc Nurs 2007;6:273-9.

79. Rolley J, Smith J, DiGiacomo M, et al. The caregiving role following percutaneous coronary intervention. J Clin Nurs 2011;20:227-35.

80. Spence A, Hasson F, Waldron M, et al. Active carers: living with chronic obstructive pulmonary disease. Int J Palliat Nurs 2008;14:368-72.

81. Strøm A, Andersen KL, Korneliussen K, et al. Being "on the alert" and "a forced volunteer": a qualitative study of the invisible care provided by the next of kin of patients with chronic heart failure. $J$ Multidiscip Healthc 2015;8:271-7.

82. Wallin E, Larsson I-M, Rubertsson S, et al. Relatives' experiences of everyday life six months after hypothermia treatment of a significant other's cardiac arrest. J Clin Nurs 2013;22:1639-46.

83. Wingham J, Frost J, Britten N, et al. Needs of caregivers in heart failure management: A qualitative study. Chronic IIIn 2015;11:304-19.

84. Näsström L, Luttik ML, Idvall E, et al. Exploring partners perspectives on participation in heart failure home care: a mixedmethod design. J Adv Nurs 2017;73:1208-19.

85. Clark AM, Reid ME, Morrison CE, et al. The complex nature of informal care in home-based heart failure management. $J$ Adv Nurs 2008;61:373-83.

86. Hess AM. The health literacy, self-care, and medication hassles of patients with heart failure and their caregivers. Masters. West Lafayette, IN: Purdue University, 2009.

87. Kneeshaw MF, Considine RM, Jennings J. Mutuality and preparedness of family caregivers for elderly women after bypass surgery. Applied Nursing Research 1999;12:128-35.

88. Park EO, Yates BC, Schumacher KL, et al. Caregiving demand and difficulty in older adult spousal caregivers after coronary artery bypass surgery. Geriatr Nurs 2013;34:383-7.

89. Riegner J. The relationship of role strain, perceived social support, and humor to quality of life among couples experiencing the lifelimiting illness of chronic obstructive pulmonary disease. PhD. Tallahassee, Florida: Florida State University, 1996.

90. Miravitlles M, Peña-Longobardo LM, Oliva-Moreno J, et al. Caregivers' burden in patients with COPD. Int J Chron Obstruct Pulmon Dis 2015;10:347-56.

91. Lum HD, Lo D, Hooker S, et al. Caregiving in heart failure: relationship quality is associated with caregiver benefit finding and caregiver burden. Heart Lung 2014;43:306-10.

92. Luttik ML, Jaarsma T, Lesman I, et al. Quality of life in partners of people with congestive heart failure: gender and involvement in care. J Adv Nurs 2009;65:1442-51.

93. Kang X, Li Z, Nolan MT. Informal caregivers' experiences of caring for patients with chronic heart failure Systematic review and metasynthesis of qualitative studies. 2011;26:386-94.

94. Aasbø G, Solbraekke KN, Kristvik E, et al. Between disruption and continuity: challenges in maintaining the 'biographical we' when caring for a partner with a severe, chronic illness. Sociol Health IIIn 2016;38:782-96.

95. Wingham J, Frost J, Britten N. Behind the smile: qualitative study of caregivers' anguish and management responses while caring for someone living with heart failure. BMJ Open 2017;7:e014126.

96. Lawton MP, Moss M, Kleban MH, et al. A two-factor model of caregiving appraisal and psychological well-being. J Gerontol 1991;46:P181-P189.

97. Lee CS, Bidwell JT, Paturzo M, Alvaro M, et al. Patterns of self-care and clinical events in a cohort of adults with heart failure: 1 year follow-up. Heart Lung 2018;47:40-6.

98. Nakken N, Janssen DJA, van den Bogaart EHA, et al. European Respiratory Review 2015;24:498-504.

99. Mahoney DF. Vigilance. Evolution and definition for caregivers of family members with Alzheimer's disease. J Gerontol Nurs 2003;29:24-30 https://doi.org/.

100. Buck HG, Harkness K, Wion R, et al. Caregivers' contributions to heart failure self-care: A systematic review. European Journal of Cardiovascular Nursing 2015;14:79-89.

101. Dixon-Woods M, Agarwal S, Jones D, et al. Synthesising qualitative and quantitative evidence: A review of possible methods. $J$ Health Serv Res Policy 2005;10:45-53.

102. Bazely P. Integrating analyses in mixed methods research. SAGE Publications London 2018. 